\title{
Eficiência agronômica de adubos nitrogenados em soqueira de cana-de-açúcar colhida sem queima
}

\author{
Michele Xavier Vieira Megda(1), Paulo Cesar Ocheuze Trivelin(2), Henrique Coutinho Junqueira Franco(3), \\ Rafael Otto ${ }^{(1)}$ e André César Vitti ${ }^{(4)}$
}

\begin{abstract}
(1)Universidade de São Paulo (Usp), Escola Superior de Agricultura Luiz de Queiroz, Departamento de Ciência do Solo, Caixa Postal 96, CEP 13418-900 Piracicaba, SP. E-mail: micheleagronomia@yahoo.com.br, otto@cena.usp.br (2)Usp, Centro de Energia Nuclear na Agricultura, Caixa Postal 9, CEP 13418-900 Piracicaba, SP. E-mail: pcotrive@cena.usp.br (3)Laboratório Nacional de Ciência e Tecnologia do Bioetanol (CTBE) - CNPEM/ABTLuS, Caixa Postal 6.170, CEP 13083-970 Campinas, SP. E-mail: henrique.franco@bioetanol.org.br ${ }^{\left({ }^{4}\right)}$ Agência Paulista de Tecnologia dos Agronegócios, Polo Centro-Sul, Caixa Postal 28, CEP 13400-970 Piracicaba, SP. E-mail: acvitti@apta.sp.gov.br
\end{abstract}

Resumo - O objetivo deste trabalho foi avaliar a eficiência agronômica das fontes nitrogenadas ureia (U), nitrato de amônio (NA), sulfato de amônio (SA) e cloreto de amônio (CA) em soqueira de cana-de-açúcar colhida sem queima, bem como determinar o efeito residual dessas fontes sobre a produtividade da cultura no ano agrícola subsequente. Utilizou-se o delineamento experimental de blocos ao acaso, com quatro repetições. Os tratamentos consistiram da aplicação de $120 \mathrm{~kg} \mathrm{ha}^{-1}$ de N a um Latossolo Vermelho distrófico, coberto por palhada resultante da colheita sem queima da primeira soqueira. Incluiu-se um tratamento de controle sem adição de $\mathrm{N}$ fertilizante. Para avaliar o efeito residual dos adubos nitrogenados, aplicaram-se $450 \mathrm{~kg} \mathrm{ha}^{-1} \mathrm{do}$ formulado 20-5-19 após o corte da cana-soca. A maior produção de colmos e de açúcar na safra 2006/2007 foi obtida com a fonte SA. Na safra 2007/2008, não foi verificado efeito residual da adubação nitrogenada e houve queda de produtividade do tratamento CA em comparação ao controle. A fonte CA, à dose de $120 \mathrm{~kg} \mathrm{ha}^{-1} \mathrm{de}$ $\mathrm{N}$ em adubação de soqueira de segundo corte, é agronomicamente tão eficiente quanto as demais fontes de $\mathrm{N}$ utilizadas, mas tem menor eficiência no ano agrícola subsequente.

Termos para indexação: Saccharum, cloreto de amônio, efeito residual, nitrogênio.

\section{Agronomic efficiency of nitrogen fertilizers on green harvesting sugarcane ratoon}

\begin{abstract}
The objective of this work was to evaluate the agronomic efficiency of the nitrogen sources urea (U), ammonium nitrate (AN), ammonium sulfate (AS), and ammonium chloride (AC) on green harvesting sugarcane ratoon, as well as the residual effect of these sources on crop productivity in the subsequent crop year. A randomized block design was used with four replicates. Treatments consisted of applying $120 \mathrm{~kg} \mathrm{ha}^{-1}$ of $\mathrm{N}$ fertilizer on a Typic Hapludox covered by straw residues resulting from the harvest without burning of the first ratoon. A control treatment was included with no $\mathrm{N}$ fertilizer. To evaluate the residual effect of the nitrogen fertilizers, $450 \mathrm{~kg} \mathrm{ha}^{-1}$ of a 20-5-19 formulation was applied to soil after sugarcane ratoon harvest. The highest production of stalks and sugar, in the 2006/2007 season, was obtained with the source AS. In the 2007/2008 harvest season, no residual effect of $\mathrm{N}$ fertilization was observed and there was a productivity decrease in the $\mathrm{AC}$ treatment in comparison to the control. The AC source, at a dose of $120 \mathrm{~kg} \mathrm{ha}^{-1} \mathrm{~N}$ in the fertilization of the second ratoon, is agronomically as efficient as the other $\mathrm{N}$ sources used, but shows less efficiency in the subsequent crop year.
\end{abstract}

Index terms: Saccharum, ammonium chloride, residual effect, nitrogen.

\section{Introdução}

Atualmente, a preocupação com o ambiente tem gerado pressão quanto ao uso de combustíveis fósseis, que contribuem para o efeito estufa e o aquecimento global, além de serem os grandes responsáveis pela emissão de gases poluentes na atmosfera. A cana-de-açúcar é a cultura mais promissora entre as produtoras de biocombustíveis renováveis, e o etanol é considerado a alternativa mais viável para a substituição dos derivados de petróleo, como gasolina e óleo diesel, com grande importância no cenário agrícola brasileiro e futuro promissor no cenário mundial.

Para reduzir a emissão de $\mathrm{CO}_{2}$ e de partículas sólidas sobre áreas urbanas, a colheita da cana-de-açúcar tem sido realizada sem a queima prévia dos resíduos 
culturais ou da palhada, em especial no Estado de São Paulo. A prática da colheita sem despalha a fogo, com a manutenção da palha da cana-de-açúcar no solo, é fundamental para a sua cobertura, o que melhora atributos físicos, químicos e biológicos e, consequentemente, de fertilidade do solo, em comparação ao sistema com queima. No entanto, há um principal fator limitante, que se relaciona à adubação nitrogenada de soqueiras, em razão da dificuldade e do custo para a aplicação do adubo incorporado ao solo. Nas condições atuais de manejo da fertilização nitrogenada em "cana crua", são raros os relatos em que a cana-de-açúcar, no final de um ciclo agrícola, utiliza mais de $40 \%$ do nitrogênio do fertilizante (Franco et al., 2008). Esse aproveitamento reduzido é atribuído, em parte, à intensa imobilização microbiológica em solo que contém material vegetal de elevada relação C:N (Courtaillac et al., 1998; Gava et al., 2001), e a perdas do N no sistema solo-planta-atmosfera (Trivelin et al., 2002). O N imobilizado, que pode ficar no solo, tornase uma fonte residual potencial para a cultura nos ciclos subsequentes da cana-de-açúcar (Vitti et al., 2007a). A maioria dos trabalhos com adubação nitrogenada em cana planta ou soqueiras avaliou somente uma safra agrícola, sem levar em consideração a possibilidade de respostas aos fertilizantes (positivas ou negativas) nos ciclos agrícolas subsequentes ao da aplicação, por meio de possível efeito residual no sistema solo-planta. Outra limitação é o fato de a ureia ser a fonte nitrogenada mais utilizada na cultura da cana-de-açúcar, já que, quando aplicada sobre os resíduos culturais presentes no solo, apresenta elevadas taxas de perda por volatilização de $\mathrm{NH}_{3}$, em decorrência da ação da urease do solo e da palha (Lara Cabezas et al., 1999; Trivelin et al., 2002).

Para a adubação nitrogenada de soqueiras colhidas sem queima, é necessário o uso de fontes nitrogenadas que apresentem menores perdas por volatilização, pois a presença da palha (10 a $\left.30 \mathrm{Mg} \mathrm{ha}^{-1}\right)$ dificulta a incorporação do adubo ao solo (Franco et al., 2007; Rochette et al., 2009). Em cana-de-açúcar colhida mecanicamente sem queima, Vitti et al. (2007a) observaram que, com a aplicação de sulfato de amônio, tanto em faixa quanto em área total, as perdas de $\mathrm{NH}_{3}$ foram inferiores às observadas com o uso de ureia. $\mathrm{Na}$ aplicação em faixa, a perda de $\mathrm{NH}_{3}$ do sulfato de amônio foi da ordem de $2 \%$ do total aplicado, comparado a $32 \%$ de perda com o uso da ureia. Ao se considerar o papel preponderante do $\mathrm{N}$ na agricultura e que mais de $70 \%$ dos fertilizantes nitrogenados usados no Brasil são importados, torna-se fundamental o desenvolvimento de pesquisas voltadas à obtenção e ao uso de fontes alternativas de $\mathrm{N}$ na agricultura, para aumentar o aproveitamento do $\mathrm{N}$-fertilizante pelas culturas e reduzir os custos de produção.

O cloreto de amônio $\left(\mathrm{NH}_{4} \mathrm{Cl}\right)$ é uma fonte alternativa de nitrogênio para a cultura da cana-de-açúcar, e contém $25 \%$ de N. Pesquisas desenvolvidas fora do país mostram boa eficiência do cloreto de amônio, que é muito usado no Japão e na Índia, na produção de arroz (Ashraf et al., 2005). No Brasil, o cloreto de amônio não é comercializado como fertilizante, sendo utilizado somente para fins industriais. Coelho et al. (2006) obtiveram, para a cultura do milho, maior eficiência agronômica do cloreto de amônio em comparação à ureia e ao bicarbonato de amônio. Vieira et al. (2010), ao avaliar a resposta da cana-de-açúcar a doses de cloreto de amônio, verificaram aumento de produtividade no primeiro ano de sua aplicação, porém com queda na produção de colmos e açúcar no ano subsequente, quando foi avaliado o efeito residual dessa fonte.

O objetivo deste trabalho foi avaliar a eficiência agronômica das fontes nitrogenadas ureia, nitrato de amônio, sulfato de amônio e cloreto de amônio em soqueira de cana-de-açúcar, bem como determinar o efeito residual dessas fontes sobre a produtividade da cultura no ano agrícola subsequente.

\section{Material e Métodos}

O experimento foi desenvolvido em condições de campo, em área comercial de cana-de-açúcar, localizada no Município de Piracicaba, SP $\left(22^{\circ} 42^{\prime} 04^{\prime \prime S}\right.$ e $47^{\circ} 33^{\prime} 29^{\prime \prime} \mathrm{W}$, a $560 \mathrm{~m}$ de altitude). A cultivar de cana-de-açúcar utilizada foi a SP89 1115 (segunda rebrota), e o solo é classificado como Latossolo Vermelho distrófico argiloso (Santos et al., 2006), cujos atributos químicos da camada arável $(0-25 \mathrm{~cm})$, antes da instalação do experimento, foram: $\mathrm{pH}$ em $\mathrm{CaCl}_{2}$ de 4,4; 32,3 $\mathrm{g} \mathrm{dm}^{-3}$ de $\mathrm{MO} ; 11,7 \mathrm{mg} \mathrm{dm}^{-3}$ de $\mathrm{P}$ resina; $50,3 \mathrm{mg} \mathrm{dm}^{-3}$ de S-SO ${ }_{4} ; 1,8 \mathrm{mmol}_{\mathrm{c}} \mathrm{dm}^{-3}$ de K ; $20 \mathrm{mmol}_{\mathrm{c}} \mathrm{dm}^{-3}$ de $\mathrm{Ca} ; 9,7 \mathrm{mmol}_{\mathrm{c}} \mathrm{dm}^{-3} \mathrm{de} \mathrm{Mg} ; 69 \mathrm{mmol}_{\mathrm{c}}$ $\mathrm{dm}^{-3}$ de $\mathrm{H}+\mathrm{Al} ; 5 \mathrm{mmol}_{\mathrm{c}} \mathrm{dm}^{-3}$ de Al; soma de bases de $31,5 \mathrm{mmol}_{\mathrm{c}} \mathrm{dm}^{-3}$; CTC de $101 \mathrm{mmol}_{\mathrm{c}} \mathrm{dm}^{-3}$; e saturação por bases de $31 \%$. 
Utilizou-se o delineamento experimental de blocos ao acaso, com quatro repetições e cinco tratamentos: cloreto de amônio (CA), nitrato de amônio (NA), sulfato de amônio (SA) e ureia (U), aplicados em dose única de $120 \mathrm{~kg} \mathrm{ha}^{-1}$ de $\mathrm{N}$ definida com base na produtividade esperada da cultura (Raij \& Cantarella, 1997), além da testemunha (TE) sem adubação nitrogenada. A área de cada parcela experimental foi de $157,5 \mathrm{~m}^{2}$, que consistiu de sete linhas (ruas) de cana-de-açúcar, com $15 \mathrm{~m}$ de comprimento e espaçamento entre linhas de 1,5 m.

A adubação mineral da segunda soqueira de cana-de-açúcar foi realizada em dezembro de 2006, e as fontes nitrogenadas foram aplicadas sobre a camada de palha, resultante da colheita mecânica da cana-de-açúcar, e ao lado da linha de soqueira (distante $25 \mathrm{~cm}$ do centro da linha de cana-de-açúcar). Em todos os tratamentos, foram aplicados $180 \mathrm{~kg} \mathrm{ha}^{-1} \mathrm{de} \mathrm{K}_{2} \mathrm{O}$ na forma de cloreto de potássio.

Avaliações do número de perfilhos e da produção de fitomassa da parte aérea durante o ciclo de crescimento da soqueira foram realizadas aos 60, 120 e 180 dias após a adubação nitrogenada (DAA). A contagem e a colheita dos perfilhos foram realizadas em uma amostra de $2 \mathrm{~m}$ lineares de sulco por parcela, e, em seguida, determinou-se a fitomassa fresca da parte aérea das plantas diretamente em campo. Realizou-se, também, a contagem de perfilhos em $20 \mathrm{~m}$ de linha de soqueira de cada parcela (dois segmentos de $10 \mathrm{~m}$ cada um), tendo-se calculado, posteriormente, o número médio de colmos por metro em cada parcela experimental. Nessas avaliações, a produção de fitomassa fresca da parte aérea foi expressa em $\mathrm{Mg} \mathrm{ha}^{-1}$. Nesse cálculo, considerou-se o número de perfilhos de cada amostra colhida em $2 \mathrm{~m}$, corrigido pelo número de plantas resultantes da contagem em $20 \mathrm{~m}$ de linha de soqueira. Essa correção foi realizada por causa da variabilidade do número de perfilhos que normalmente ocorre em canaviais comerciais.

Para estimar o crescimento e o acúmulo de fitomassa (massa vegetal com umidade natural ou "fitomassa fresca" da parte aérea da cana-soca) durante o período experimental, foi utilizada a função logística: $\mathrm{Y}=\mathrm{Ymax} /\left(1+(\mathrm{DAC} / \mathrm{A})^{\mathrm{B}}\right)$, em que: $\mathrm{Y}$ é a fitomassa fresca da parte aérea da cana-soca em $\mathrm{Mg} \mathrm{ha}^{-1}$; DAC é o número de dias após o corte da cana-de-açúcar; e Ymax é a fitomassa máxima produzida no período.

As constantes A e B da função foram estimadas por meio de programa computacional de acordo com
Zullo Junior \& Arruda (1987). Dessa forma, para cada tratamento, foi gerada uma equação que descreveu a variação, no tempo, da fitomassa da parte aérea da cana-soca. $O$ índice fisiológico utilizado para avaliar possíveis diferenças entre os tratamentos foi a taxa de produção de fitomassa (TPF), obtida pela manipulação das funções de ajuste, segundo modelo descrito por Lucchesi (1984). A TPF é um índice que avalia o crescimento do vegetal relacionando à quantidade de fitomassa acumulada, em razão da área de solo, por unidade de tempo (Lucchesi, 1984), e não requer conhecimento da área foliar da planta para sua avaliação.

Em novembro de 2007 (342 dias após a adubação nitrogenada), para a avaliação da produção final de colmos ( $\mathrm{TCH}$, toneladas de colmo por hectare), foram coletadas quatro linhas centrais de $15 \mathrm{~m}$ por parcela (60 m de sulco). A cana-de-açúcar foi colhida mecanicamente com colhedora modelo Case A7700 (Case IH, Sorocaba, SP), sem queima prévia do canavial, e as determinações da produtividade foram efetuadas em caminhão transbordo instrumentado, contendo célula de carga.

Para o cálculo da margem de contribuição agrícola (MCA), com base nos preços em março de 2009, foram utilizados: produtividade de colmos por hectare na safra 2006/2007 ( $\left.\mathrm{Mg} \mathrm{ha}^{-1}\right)$; açúcar total recuperável (ATR) por megagrama de colmos $\left(\mathrm{kg} \mathrm{Mg}^{-1}\right)$; ATR $\left(\mathrm{kg} \mathrm{ha}^{-1}\right)$, obtido por meio da multiplicação do $\mathrm{TCH}\left(\mathrm{Mg} \mathrm{ha}^{-1}\right)$ pelo ATR $\left(\mathrm{kg} \mathrm{Mg}^{-1}\right)$; preço do quilo do ATR (R\$ 0,2746 $\mathrm{kg}^{-1}$ de ATR); custo do corte, carregamento e transporte (CCT) (R\$ 15,80 $\mathrm{Mg}^{-1}$ fornecido pelo Departamento Agrícola da Usina Iracema, Iracemópolis, SP); e custo da adubação nitrogenada ( $\mathrm{R} \$ 3,75 \mathrm{~kg}^{-1}$ de $\mathrm{N}$-cloreto de amônio, R\$ $3,33 \mathrm{~kg}^{-1}$ de N-sulfato de amônio, $\mathrm{R} \$ 2,06 \mathrm{~kg}^{-1}$ de N-nitrato de amônio e R $\$ 2,17 \mathrm{~kg}^{-1}$ de $\mathrm{N}$-ureia). $\mathrm{O}$ modelo de cálculo da MCA foi realizado conforme Fernandes (2003).

Após a colheita da cana-soca (segunda rebrota), em novembro de 2007, realizou-se a amostragem de solo para fins de caracterização química de fertilidade, na profundidade de 0-25 cm, tendo-se coletado amostras compostas de solo (três pontos por parcela) em todas as parcelas do experimento implantado em 2006. As amostras foram coletadas, a $25 \mathrm{~cm}$ do centro do sulco, sempre de um mesmo lado da linha de cana em que foram aplicados os fertilizantes. Os atributos químicos do solo da camada arável $(0-25 \mathrm{~cm})$ após a 
colheita da segunda rebrota de cana-de-açúcar estão descritos na Tabela 1.

Após a colheita, foi realizada a aplicação de 2,3 $\mathrm{Mg} \mathrm{ha}^{-1}$ de calcário dolomítico para elevar a saturação por bases para $60 \%$. Em dezembro de 2007, realizouse a adubação da terceira rebrota, tendo-se aplicado $450 \mathrm{~kg} \mathrm{ha}^{-1}$ da mistura de grânulos 20-05-19, o que forneceu 90, 22 e $86 \mathrm{~kg} \mathrm{ha}^{-1}$ de $\mathrm{N}, \mathrm{P}_{2} \mathrm{O}_{5}$ e $\mathrm{K}_{2} \mathrm{O}$, na forma de nitrato de amônio, superfosfato triplo e cloreto de potássio, respectivamente. As doses foram determinadas de acordo com a análise do solo e a produtividade esperada (Raij \& Cantarella, 1997), e foram aplicadas em todos os tratamentos, inclusive na testemunha, para avaliar possível efeito residual das fontes nitrogenadas, aplicadas no ciclo anterior, no sistema solo-planta.

A aplicação foi realizada em faixa, sobre a palha, ao lado da linha de soqueira de cana-de-açúcar, distante $25 \mathrm{~cm}$ do centro da linha de cana-de-açúcar. Em novembro de 2008, aos 348 DAA, foi avaliada a produção final de colmos (TCH), tendo-se coletado os colmos de cana-de-açúcar em quatro linhas centrais de $15 \mathrm{~m}$ por parcela $(60 \mathrm{~m}$ de sulco). A colheita da cana-de-açúcar foi realizada com colhedora mecânica, modelo Case A7700 (Case IH, Sorocaba, SP), sem queima prévia do canavial, e as avaliações de produtividade foram efetuadas como descrito anteriormente para a segunda soca, em caminhão instrumentado contendo célula de carga.

Durante todo o período experimental, as variáveis meteorológicas, radiação solar, velocidade do vento, umidade relativa do ar, temperatura e precipitação pluvial, foram mensuradas por meio de estações meteorológicas automáticas instaladas próximas à área experimental. A evapotranspiração de referência $\left(\mathrm{ET}_{0}\right)$ foi calculada pelo método de Penman-Monteith, e o balanço hídrico climatológico no ciclo de segunda soca (Figura 1 A) foi calculado mediante o uso de planilhas eletrônicas (Rolim et al., 1998).

Os resultados foram submetidos à análise de variância pelo teste F, com uso do programa SAS. Posteriormente, para as causas de variação significativas, aplicou-se o teste de Tukey, a 10\% de probabilidade, para comparar o efeito das fontes de $\mathrm{N}$.

Tabela 1. Atributos químicos do solo da camada de $0-25 \mathrm{~cm}$ de profundidade para os tratamentos com fontes de $\mathrm{N}$ e testemunha após a colheita da segunda soqueira de cana-de-açúcar em novembro de 2007.

\begin{tabular}{|c|c|c|c|c|c|c|c|c|c|c|c|}
\hline Tratamentos & $\begin{array}{c}\mathrm{MO} \\
\left(\mathrm{g} \mathrm{dm}^{-3}\right)\end{array}$ & $\begin{array}{c}\mathrm{pH} \\
\mathrm{CaCl}_{2}\end{array}$ & 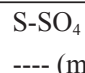 & $\begin{array}{c}\mathrm{P} \\
-3) \\
---\end{array}$ & $\mathrm{K}$ & $\mathrm{Ca}$ & $\begin{aligned} & \mathrm{Mg} \\
&-(\mathrm{mm}\end{aligned}$ & $\begin{array}{c}\mathrm{H}+\mathrm{Al} \\
\left.\mathrm{n}^{-3}\right) \\
-\end{array}$ & SB & CTC & $\begin{array}{c}\mathrm{V} \\
(\%)\end{array}$ \\
\hline Testemunha & 33,8 & 4,5 & 32,0 & 17,8 & 2,0 & 24,5 & 11,0 & 57,5 & 37,5 & 95,0 & 39,3 \\
\hline Cloreto de amônio & 35,0 & 4,5 & 25,3 & 19,5 & 2,1 & 23,8 & 9,0 & 65,0 & 34,8 & 99,8 & 34,5 \\
\hline Nitrato de amônio & 33,8 & 4,5 & 37,3 & 25,3 & 2,1 & 21,3 & 8,8 & 60,5 & 32,1 & 92,6 & 35,0 \\
\hline Sulfato de amônio & 34,0 & 4,4 & 60,5 & 17,3 & 1,8 & 19,8 & 8,3 & 71,5 & 29,8 & 101,3 & 30,3 \\
\hline Ureia & 33,3 & 4,6 & 20,8 & 15,8 & 1,7 & 27,0 & 9,8 & 59,5 & 38,4 & 97,9 & 39,8 \\
\hline
\end{tabular}
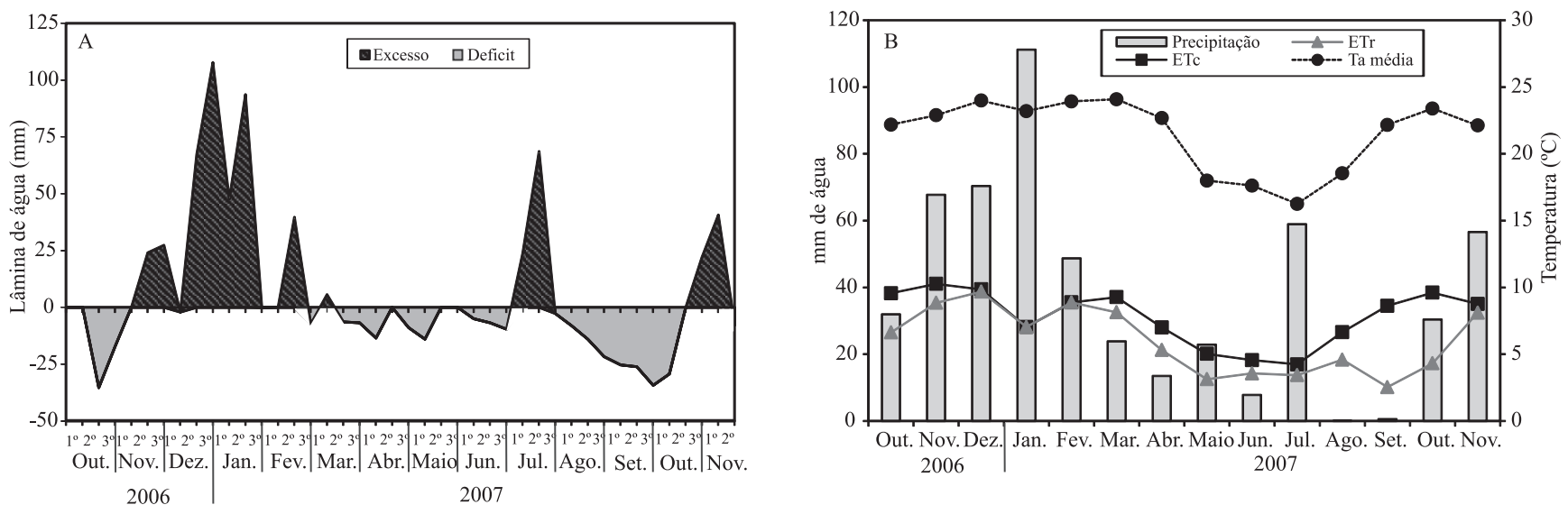

Figura 1. Balanço hídrico da área experimental no ciclo agrícola de segunda rebrota de cana-de-açúcar, na safra $2006 / 2007$. Excesso, excedente hídrico do solo; Deficit, deficit hídrico do solo (A); ETc, evapotranspiração potencial da cultura; ERr, evapotranspiração real da cultura (B). 


\section{Resultados e Discussão}

Independentemente da fonte de $\mathrm{N}$, o número de perfilhos da segunda rebrota da cana-de-açúcar foi maior aos 60 DAA, e houve redução significativa no número de perfilhos até os 120DAA(Tabela 2). Segundo Machado et al. (1982), nos estádios iniciais da cultura, há uma superprodução de perfilhos, que, no decorrer do desenvolvimento, sofrem mortalidade natural, oriunda da competição intraespecífica. A rapidez com que a cana-soca atingiu máximo perfilhamento ocorreu em razão do seu sistema radicular já estar estabelecido, associado, também, às ótimas condições ambientais, por meio da combinação entre suprimento hídrico adequado e altas temperaturas na fase de brotação e perfilhamento. A temperatura média entre novembro de 2006 e abril de 2007, correspondentes aos primeiros 180 dias do ciclo da cultura, oscilou entre 23 e $25^{\circ} \mathrm{C}$ (Figura $1 \mathrm{~B}$ ), e as temperaturas máximas atingiram valores superiores a $30^{\circ} \mathrm{C}$ em praticamente todos os meses. O balanço hídrico local apresentou um curto período de deficit hídrico (Figura $1 \mathrm{~A}$ ). Além disso, para a brotação das soqueiras, deve-se considerar o direcionamento das reservas da planta para a parte subterrânea (raízes e rizomas) e sua posterior reutilização pelo ciclo subsequente (Trivelin et al., 2002). Ramesh \& Mahadevaswamy (2000) e Simões et al. (2005) observaram que o número de perfilhos por planta aumentou continuadamente dos 60 aos 120 dias e decresceu gradualmente a partir desse ponto pelo efeito de competição e sombreamento.

Houve diferença na produção de fitomassa da parte aérea entre tratamentos com fontes de $\mathrm{N}$ nas duas primeiras épocas de avaliação (Tabela 2), e o SA foi a fonte que resultou na maior produtividade aos 60 DAA, tendo diferido do nitrato de amônio. Esses resultados podem ser explicados pelo fato de o enxofre do sulfato de amônio melhorar a absorção e o aproveitamento do $\mathrm{N}$ pelas culturas em decorrência da sinergia positiva entre esses nutrientes (Vitti et al., 2007a).

O máximo incremento na fitomassa da parte aérea ocorreu dos 60 aos 120 DAA (Tabela 2), período em que a pluviosidade acumulada foi em torno de $700 \mathrm{~mm}$. Houve redução nos ganhos em fitomassa dos 120 aos 180 DAA (junho), resultante das condições de tempo seco e frio (Figura $1 \mathrm{~B}$ ), quando tem início o acúmulo de sacarose. O cloreto de amônio foi a fonte nitrogenada que mostrou o maior acúmulo de fitomassa da parte aérea, que foi $24,7 \%$ superior em comparação às plantas do tratamento sem $\mathrm{N}$-fertilizante aos 180 DAA

A ureia apresentou eficiência semelhante na produção de fitomassa da parte aérea nas três épocas de avaliação, quando comparada aos demais tratamentos (Tabela 2). Apesar de o tratamento ureia ter apresentado menor número de perfilhos por metro linear, o peso de cada perfilho foi maior, o que compensou o menor número de perfilhos por hectare e resultou em produção de massa similar a dos tratamentos com as outras fontes nitrogenadas. Além disso, as intensas chuvas ocorridas logo após a aplicação do fertilizante promoveram a incorporação da ureia aplicada superficialmente, o que reduziu as perdas por volatilização de $\mathrm{NH}_{3}$ (Prasertsak et al., 2002; Sommer et al., 2004; Cantarella et al., 2008).

$\mathrm{Na}$ análise quantitativa do crescimento da segunda soqueira, a primeira fase do acúmulo de fitomassa, da rebrota até os $90 \mathrm{DAA}$, foi representada por um rápido acúmulo, quando se dá a total cobertura do solo pela

Tabela 2. Número de perfilhos por metro e produção de fitomassa da parte aérea da cana-de-açúcar nas épocas de avaliação realizadas aos 60, 120 e 180 dias após a adubação nitrogenada, e produtividade de colmos (TCH) e rendimento em sacarose (TPH) na colheita final, em novembro de $2007^{(1)}$.

\begin{tabular}{|c|c|c|c|c|c|c|c|}
\hline \multirow[t]{2}{*}{ Fontes de $\mathrm{N}$} & \multicolumn{2}{|c|}{ № de perfilhos por $\mathrm{m}$} & \multicolumn{3}{|c|}{ Produção de fitomassa $\left(\mathrm{Mg} \mathrm{ha}^{-1}\right)$} & $\mathrm{TCH}$ & TPH \\
\hline & 60 & 120 & 60 & 120 & 180 & \multicolumn{2}{|c|}{---------(Mg ha'-1)--------- } \\
\hline Testemunha & $16 \mathrm{~b}$ & $12 \mathrm{c}$ & $59,8 b$ & $89,3 b$ & $114,1 \mathrm{c}$ & $89,6 b$ & $15,7 b$ \\
\hline Cloreto de amônio & $19 \mathrm{a}$ & $15 \mathrm{a}$ & $69,8 \mathrm{ab}$ & $114,9 \mathrm{a}$ & $142,3 \mathrm{a}$ & $101,5 \mathrm{a}$ & $17,8 \mathrm{a}$ \\
\hline Nitrato de amônio & $19 \mathrm{a}$ & $14 \mathrm{ab}$ & $57,9 \mathrm{~b}$ & $110,8 \mathrm{a}$ & $126,3 b$ & $97,4 \mathrm{ab}$ & $17,3 \mathrm{ab}$ \\
\hline Sulfato de amônio & $19 \mathrm{a}$ & $14 \mathrm{ab}$ & $76,4 \mathrm{a}$ & $107,9 \mathrm{a}$ & $129,5 b$ & $106,1 \mathrm{a}$ & $18,4 \mathrm{a}$ \\
\hline Ureia & $18 \mathrm{ab}$ & $13 \mathrm{bc}$ & $69,9 \mathrm{ab}$ & $95,4 \mathrm{ab}$ & $134,1 \mathrm{~b}$ & $105,0 \mathrm{a}$ & $17,5 \mathrm{ab}$ \\
\hline$\overline{C V}(\%)$ & 8,0 & 11,2 & 19,5 & 14,2 & 11,4 & 7,1 & 8,6 \\
\hline Valor F & $2,8^{*}$ & $2,7 *$ & $1,4 *$ & $2,1 *$ & $6,9 * * *$ & $3,6^{* *}$ & $2,4^{*}$ \\
\hline
\end{tabular}

${ }^{(1)}$ Médias seguidas de letras iguais, nas colunas, não diferem, entre si, pelo teste de Tukey, a $10 \%$ de probabilidade. *, ** e ***Significativo a 10,5 e $1 \%$ de probabilidade, respectivamente. 
folhagem da cana, como consequência do máximo perfilhamento (Figura $2 \mathrm{~A}$ ). A segunda fase (90 aos 240 DAA) foi caracterizada por menor acúmulo de fitomassa, quando continuam o crescimento e o desenvolvimento dos colmos sobreviventes, que ganham altura, e ocorre o início do acúmulo de açúcar na base dos colmos. Já na terceira fase (240 aos 365 DAA), quando as touceiras atingem altura máxima, ocorre o amarelecimento e a consequente senescência das folhas que se encontram na altura mediana da planta, o que indica que já está sendo depositado açúcar nessa região. É importante destacar que, durante todo o ciclo da segunda soqueira de cana-de-açúcar, o tratamento testemunha foi o que apresentou a menor produção de fitomassa da parte aérea, o que evidencia a importância da adubação nitrogenada no incremento do perfilhamento e na produção de fitomassa da cana-de-açúcar.

A TPF ocorreu de forma mais acentuada para todos os tratamentos até os $30 \mathrm{DAA}$, e o tratamento CA foi o que apresentou maior potencial de produção (Figura 2 B). O desenvolvimento das folhas determina a área de interceptação da radiação solar e a dimensão do aparelho fotossintetizador e, portanto, sua dimensão se estabelece nos estádios iniciais de desenvolvimento da cultura. Até os 100 dias, a massa das folhas representa mais que $70 \%$ do total da planta; depois desse estádio, a quantidade relativa à massa das folhas diminui progressivamente até que, aproximadamente aos 400 dias, as folhas passam a representar apenas $9 \%$ da massa total da planta, o que reduz, substancialmente, o acúmulo de fitomassa (Machado et al., 1982). A produtividade da cana-de-açúcar é muito influenciada pelas condições meteorológicas prevalecentes durante os vários subperíodos de seu crescimento. Dessa forma, o conhecimento das fases de crescimento fenológicas é essencial para um manejo mais adequado e para a consequente maximização da produção de cana-de-açúcar.

A produtividade de colmos foi positivamente influenciada pela adubação nitrogenada (Tabela 2). Com exceção da fonte NA, todos os tratamentos diferiram da testemunha. Embora a produtividade do tratamento SA não tenha diferido significativamente do tratamento NA, a fonte SA produziu, na diferença das médias, aproximadamente $9 \mathrm{Mg} \mathrm{ha}^{-1}$ a mais de colmos, valor este que deve ser levado em consideração quando computado o custo:benefício da adubação com esta fonte, o que pode resultar em retorno econômico significativo, dependendo do tamanho da área de produção.

O tratamento ureia apresentou a mesma eficiência quando comparado às demais fontes de nitrogênio, tendo diferido da testemunha (Tabela 2). A elevada pluviosidade, após a aplicação da ureia, promoveu a incorporação da fonte amídica no solo, o que diminuiu as perdas por volatilização de amônia. Existe ainda a possibilidade da absorção pela folhagem das plantas do $\mathrm{NH}_{3}$ volatilizado da ureia (Ping et al., 2000; Fenilli et al., 2007), uma vez que a adubação foi realizada
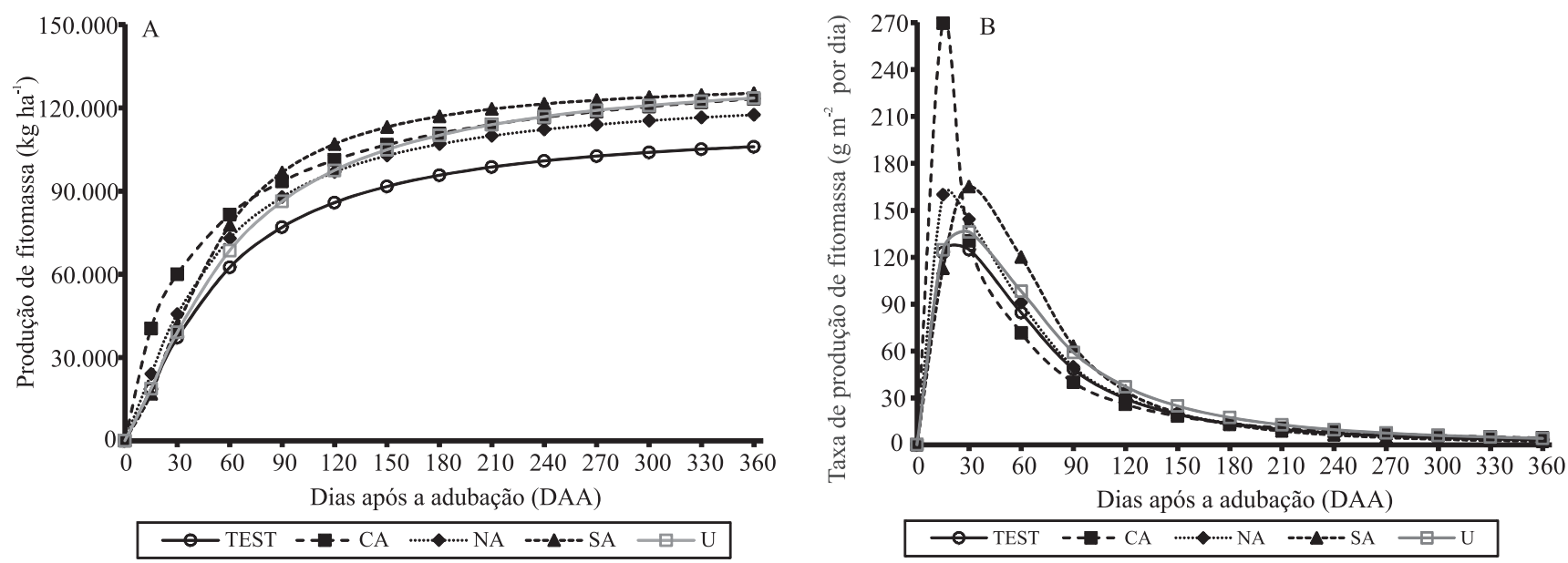

Figura 2. Acúmulo de fitomassa (A) e taxa de produção de fitomassa da parte aérea da cana-de-açúcar (B) durante o ciclo agrícola da segunda soqueira em função das fontes de nitrogênio aplicadas (CA, cloreto de amônio; NA, nitrato de amônio; AS, sulfato de amônio e U, ureia) e testemunha. 
quando as plantas já haviam brotado e estavam, aproximadamente, com $50 \mathrm{~cm}$. Coelho et al. (2006) obtiveram maior eficiência agronômica na cultura de milho para o cloreto de amônio, em comparação à ureia. Estes autores atribuíram a maior eficiência do $\mathrm{NH}_{4} \mathrm{Cl}$ à ausência de volatilização de $\mathrm{NH}_{3}$ da fonte, a qual pode ter ocorrido com os outros fertilizantes amídicos/amoniacais nas condições experimentais do trabalho. Entretanto, Barati et al. (2006), ao estudar o efeito de fontes de nitrogênio (ureia revestida com enxofre, cloreto de amônio e ureia), na produtividade do arroz, concluíram que o tratamento cloreto de amônio resultou em menor produção de grãos quando comparado às demais fontes.

As margens de contribuição agrícola foram positivas para todos os tratamentos, inclusive para a testemunha, não tendo diferido entre si (Tabela 3). Apesar de a adubação nitrogenada ter estimulado o aumento de produtividade da segunda soqueira de cana-de-açúcar (Tabela 2), o ganho em TCH não foi suficiente para cobrir o custo da adubação nitrogenada no primeiro ano de sua aplicação, o que indica a necessidade de estudos a longo prazo que levem em consideração a possibilidade de ocorrer resposta aos fertilizantes nos ciclos agrícolas subsequentes.

$\mathrm{O}$ rendimento de sacarose foi influenciado pelas fontes de nitrogênio apenas em função da diferença na produtividade de colmos (Tabela 2), já que não foi observada diferença significativa em relação aos atributos tecnológicos. A adubação nitrogenada normalmente está associada ao maior crescimento vegetativo, o que determina, invariavelmente, plantas com maior teor de umidade, porém com prejuízos no acúmulo de sacarose (Malavolta \& Moraes,
2007). Outros autores também constataram os efeitos deletérios da adubação nitrogenada, sobretudo com aplicação de doses elevadas (>120 $\mathrm{kg} \mathrm{ha}^{-1}$ de $\left.\mathrm{N}\right)$, no acúmulo de sacarose pela cana-de-açúcar, em que o Brix, o Pol do caldo, o Pol da cana e o ATR foram menores em comparação aos demais tratamentos (Franco et al., 2008).

Em relação a um possível efeito residual das fontes nitrogenadas na produtividade do ciclo subsequente (terceira soqueira), o tratamento sulfato de amônio apresentou maior produtividade de colmos, tendo diferido dos tratamentos $\mathrm{U}$ e $\mathrm{CA}$, mas não da testemunha (sem aplicação de $\mathrm{N}$-fertilizante). Isso evidencia que o nitrogênio do sistema solo-planta foi suficiente para promover o aumento de produtividade observado em relação ao primeiro ano da aplicação dos fertilizantes, e, portanto, não houve efeito residual dos fertilizantes nitrogenados. Vitti et al. (2007b) constataram que, com a aplicação de sulfato de amônio, tanto em faixa quanto em área total, as perdas por volatilização de $\mathrm{NH}_{3}$ foram muito menores que as observadas com o uso de ureia. Estes autores também verificaram que o SA proporcionou efeito residual positivo na produtividade do ciclo subsequente (quarta soca), comparado à ureia e ao nitrato de amônio, o que indica aumento na eficiência de aproveitamento do $\mathrm{N}$ pelas plantas.

A menor eficiência do cloreto de amônio na terceira rebrota de cana-de-açúcar, no presente trabalho, pode ter ocorrido em função da elevada concentração do íon cloreto $(65 \%)$ adicionado ao solo, que se somou ao mesmo íon da fonte de potássio $(\mathrm{KCl})$. Um possível efeito tóxico do cloreto $\left(\mathrm{Cl}^{-}\right)$no solo pode ter resultado em menor produtividade somente no terceiro corte, em

Tabela 3. Rendimento financeiro (MCA) em função da adubação nitrogenada no ciclo da segunda rebrota de cana-de-açúcar.

\begin{tabular}{|c|c|c|c|c|c|c|c|c|}
\hline Tratamento & $\begin{array}{c}\mathrm{TCH} \\
\left(\mathrm{Mg} \mathrm{ha}^{-1}\right)\end{array}$ & $\begin{array}{c}\text { ATR } \\
\left(\mathrm{kg} \mathrm{Mg}^{-1}\right)\end{array}$ & $\begin{array}{c}\text { ATR } \\
\left(\mathrm{kg} \mathrm{ha}^{-1}\right)\end{array}$ & Receita bruta & Custo CCT & $\begin{array}{l}\text { Custo adubo } \\
--\left(\mathrm{R} \$ \mathrm{ha}^{-1}\right) \text {--- }\end{array}$ & Custo total & $\mathrm{MCA}^{(1)}$ \\
\hline Testemunha & 89,6 & 173,9 & $15.581,4$ & $4.278,6$ & $1.415,7$ & 0,0 & $1.415,7$ & $2.862,9$ \\
\hline Cloreto de amônio & 101,5 & 173,9 & $17.650,8$ & $4.846,9$ & $1.603,7$ & 450,0 & $2.053,7$ & $2.793,2$ \\
\hline Nitrato de amônio & 97,4 & 175,9 & $17.132,7$ & $4.704,6$ & $1.538,9$ & 247,2 & $1.786,1$ & $2.918,5$ \\
\hline Sulfato de amônio & 106,1 & 172,0 & $18.249,2$ & $5.011,2$ & $1.676,4$ & 399,6 & $2.076,0$ & $2.935,2$ \\
\hline Ureia & 105,0 & 166,9 & $17.524,5$ & $4.812,2$ & $1.659,0$ & 260,4 & $1.919,4$ & $2.892,8$ \\
\hline
\end{tabular}

(1) Valor F, 0,15 ${ }^{\text {ns }}$; coeficiente de variação, 10,2\%; diferença mínima significativa (DMS), 560,6. nnão significativo. TCH, toneladas de colmos industrializáveis por hectare; ATR, açúcar total recuperável; ATR $\left(\mathrm{kg} \mathrm{ha}^{-1}\right)=\mathrm{TCH} \times \mathrm{ATR}\left(\mathrm{kg} \mathrm{Mg}^{-1}\right)$; receita bruta $=$ ATR $\left(\mathrm{kg} \mathrm{ha}^{-1}\right)$ x 0,2746 (preço médio do ATR em março 2009). CCT, custo do corte, carregamento e transporte $\left(\mathrm{CCT}=\mathrm{R} \$ 15,80 \mathrm{Mg}^{-1}\right.$ preço médio da Usina Iracema); custo CCT $=\mathrm{CCT}(\mathrm{R} \$) \mathrm{x}$ TCH. Custo dos fertilizantes em março de 2009: ureia $=\mathrm{R} \$ 1.000 \mathrm{Mg}^{-1}$ ou $\mathrm{R} \$ 2,17 \mathrm{~kg}^{-1}$ de $\mathrm{N}$; sulfato de amônio $=\mathrm{R} \$ 700,0 \mathrm{Mg}^{-1}$ ou $\mathrm{R} \$ 3,33 \mathrm{~kg}^{-1}$ de $\mathrm{N}$; nitrato de amônio $=$ $\mathrm{R} \$ 700,0 \mathrm{Mg}^{-1}$ ou R $\$ 2,06 \mathrm{~kg}^{-1}$ de N; cloreto de amônio $=\mathrm{R} \$ 937,5 \mathrm{Mg}^{-1}$ ou R $\$ 3,75 \mathrm{~kg}^{-1}$ de N . Custo total = CCT + adubo. MCA (margem de contribuição agrícola $=$ receita bruta - custo total. 
razão do efeito acumulativo deste íon nos dois ciclos de produção. Em 2006, a aplicação de $120 \mathrm{~kg} \mathrm{ha}^{-1} \mathrm{de} \mathrm{N}$, na forma de CA, correspondeu a cerca de $312 \mathrm{~kg} \mathrm{ha}^{-1}$ de $\mathrm{Cl}^{-}$, além de $120 \mathrm{~kg} \mathrm{ha}^{-1} \mathrm{de}^{-} \mathrm{Cl}^{-}$na forma de cloreto de potássio (180 $\left.\mathrm{kg} \mathrm{ha}^{-1} \mathrm{de}_{2} \mathrm{O}\right)$. Após o terceiro corte, em 2007, foi aplicado, novamente, $57 \mathrm{~kg} \mathrm{ha}^{-1} \mathrm{de}^{-}$ via cloreto de potássio $\left(86 \mathrm{~kg} \mathrm{ha}^{-1}\right.$ de $\left.\mathrm{K}_{2} \mathrm{O}\right)$. Ou seja, a quantidade total de cloreto nas duas adubações foi de aproximadamente $490 \mathrm{~kg} \mathrm{ha}^{-1} \mathrm{de}^{-}$. Mesmo que a planta tenha extraído uma parte deste cloro, quantidade significativa foi reciclada no sistema solo-planta e pode ser a principal causa da menor produtividade nas parcelas que receberam a fonte CA, já que o íon cloreto, em elevadas concentrações no solo, pode levar à acumulação de sais na rizosfera, o que causa estresse hídrico às plantas e, consequentemente, prejudica $\mathrm{o}$ crescimento e o desenvolvimento da cultura (Santana et al., 2007).

Vitti et al. (2008), ao avaliar a eficiência da fonte cloreto de amônio nas culturas do trigo e da cevada, em adubação de cobertura, verificaram que essa fonte, apesar de seu alto teor de cloro, apresentou resultados semelhantes aos da ureia. Nesse sentido, são necessários mais estudos para entender melhor a resposta da adubação nitrogenada com cloreto de amônio, não somente dentro de um ciclo, mas em ciclos consecutivos (efeito aditivo), uma vez que a cana-de-açúcar é uma cultura semiperene.

A maior produtividade de colmos na terceira soqueira de cana-de-açúcar, em comparação à segunda, se deu principalmente em decorrência da melhor distribuição de chuva durante o ciclo vegetativo da cultura, a qual apresenta maior demanda de água na fase de perfilhamento e crescimento dos colmos; o deficit hídrico somente foi observado na fase de maturação da cultura, sendo necessário para o maior acúmulo de sacarose nos colmos (Tabela 4).

Houve efeito significativo das fontes nitrogenadas na produtividade acumulada de colmos das safras 2006/2007 e 2007/2008 (Tabela 4), e o tratamento sulfato de amônio foi o que proporcionou a maior produtividade $\left(244,7 \mathrm{Mg} \mathrm{ha}^{-1}\right)$, com $21 \mathrm{Mg} \mathrm{ha}^{-1}$ a mais quando comparado à testemunha $\left(223,6 \mathrm{Mg} \mathrm{ha}^{-1}\right)$. Houve maior rendimento, em sacarose, para o tratamento sulfato de amônio, que diferiu significativamente do cloreto de amônio, o qual apresentou menor rendimento de açúcar por área, mas não diferiu dos demais tratamentos.
Tabela 4. Produtividade de colmos $(\mathrm{TCH})$ e rendimento em sacarose (TPH) da terceira rebrota (safra 2007/2008) e TCH e TPH acumuladas (safra 2006/2007 + 2007/2008) em função do N-residual de fontes nitrogenadas aplicadas na segunda rebrota (safra 2006/2007).

\begin{tabular}{lccccc}
\hline Fontes de N & \multicolumn{2}{c}{$2007 / 2008$} & & \multicolumn{2}{c}{$2006 / 2007+2007 / 2008$} \\
\cline { 2 - 3 } \cline { 5 - 6 } & TCH & TPH & & TCH & TPH \\
\hline Testemunha & $134,1 \mathrm{ab}$ & 22,8 & & $223,6 \mathrm{~b}$ & $22,7 \mathrm{a}$ \\
Cloreto de amônio & $123,1 \mathrm{c}$ & 20,9 & & $224,7 \mathrm{~b}$ & $20,8 \mathrm{~b}$ \\
Nitrato de amônio & $130,7 \mathrm{ab}$ & 22,3 & & $228,1 \mathrm{~b}$ & $22,3 \mathrm{ab}$ \\
Sulfato de amônio & $138,6 \mathrm{a}$ & 23,4 & & $244,7 \mathrm{a}$ & $23,4 \mathrm{a}$ \\
Ureia & $128,1 \mathrm{~b}$ & 21,9 & & $233,2 \mathrm{ab}$ & $21,9 \mathrm{ab}$ \\
\hline Valor F & $2,4^{*}$ & $1,7^{\text {ns }}$ & & $2,12^{*}$ & $1,6^{*}$ \\
CV (\%) & 5,7 & 6,7 & & 5,1 & 6,8 \\
DMS & 14,4 & 2,9 & & 16,7 & 1,9 \\
\hline
\end{tabular}

${ }^{(1)}$ Médias seguidas de letras iguais, nas colunas, não diferem, entre si, pelo teste de Tukey, a $10 \%$ de probabilidade. ${ }^{\text {ns}}$ Não significativo. $*$ Significativo a $10 \%$ de probabilidade. DMS, diferença mínima significativa.

\section{Conclusões}

1. A fonte alternativa, cloreto de amônio, resulta em produtividade de soqueira de cana-de-açúcar compatível com os adubos nitrogenados comerciais ureia, nitrato de amônio e sulfato de amônio, embora apresente efeito depressivo na produção de colmos no ano subsequente ao de sua aplicação, o que não ocorre com as demais fontes.

2. Não há efeito residual das fontes nitrogenadas na produtividade de colmos e de açúcar em soqueira de cana-de-açúcar de terceiro corte, e é mais viável a utilização das fontes comerciais, ureia ou sulfato de amônio, que apresentam maior produção de colmos acumulada nas duas safras agrícolas.

\section{Agradecimentos}

Ao Conselho Nacional de Desenvolvimento Científico e Tecnológico (CNPq), pela concessão de bolsa; ao Centro de Tecnologia Canavieira de Piracicaba, pelo apoio logístico; à Raudi Indústria e Comércio Ltda. e ao Centro de Pesquisa e Promoção do Sulfato de Amônio, pelo apoio financeiro.

\section{Referências}

ASHRAF, M.Y.; ALVI, A.K.; SARWAR, G.; QURESHI, M.S.; ASHRAF, M.; HUSSAIN, M. Effect of ammonium chloride on the growth and nutrient uptake by cotton grown in alkaline soil. Agrochimica, v.49, p.153-164, 2005. 
BARATI, V.; EMAM, Y.; MAFTOUN, M. Responses of two lowland: rice cultivars to the different sources and levels of nitrogen. Agrochimica, v.50, p.158-164, 2006.

CANTARELLA, H.; TRIVELIN, P.C.O.; CONTIN, T.L.M.; DIAS, F.L.F.; ROSSETTO, R.; COIMBRA, R.B.; QUAGIO, J.A. Ammonia volatilization from urease inhibitor-treated urea applied to sugarcane trash blankets. Scientia Agricola, v.65, p.397-401, 2008 .

COELHO, A.M.; RIBEIRO, B.N.; RESENDE, F.A.; TEIXEIRA, G.K.P. Eficiência agronômica do cloreto de amônio e bicarbonato de amônio como fontes de nitrogênio para a cultura do milho. Sete Lagoas: Embrapa Milho e Sorgo, 2006. 6p. (Embrapa Milho e Sorgo. Comunicado técnico, 136).

COURTAILLAC, N.; BARAN, R.; OLIVER, R.; CASABIANCA, H.; GANRY, F. Efficiency of nitrogen fertilizer in sugarcane-vertical system in Guadeloupe according to growth and ratoon age of the cane. Nutrient Cycling in Agroecosystems, v.52, p.9-17, 1998.

FENILLI, T.A.B.; REICHARDT, K.; TRIVELIN, P.C.O.; FAVARIN, J.L. Volatilization of ammonia derived from fertilizer and its reabsorption by coffee plants. Communications in Soil Science and Plant Analysis, v.38, p.1741-1751, 2007.

FERNANDES, A.C. Cálculos na agroindústria de cana-de-açúcar. 2.ed. Piracicaba: Stab, 2003. 240p.

FRANCO, H.C.J.; TRIVELIN, P.C.O.; FARONI, C.E.F.; VITTI, A.C.; OTTO, R. Aproveitamento pela cana-de-açúcar da adubação nitrogenada de plantio. Revista Brasileira de Ciência do Solo, v.32, p.2763-2770, 2008.

FRANCO, H.C.J.; VITTI, A.C.; FARONI, C.E.; CANTARELLA, H.; TRIVELIN, P.C.O. Estoque de nutrientes em resíduos culturais incorporados ao solo na reforma de áreas com cana-de-açúcar. STAB, v.25, p.32-36, 2007.

GAVA, G.J. de C.; TRIVELIN, P.C.O.; OLIVEIRA, M.W. de; PENATTI, C.P. Crescimento e acúmulo de nitrogênio em cana-de-açúcar cultivada em solo coberto com palhada. Pesquisa Agropecuária Brasileira, v.36, p.1347-1354, 2001.

LARA CABEZAS, W.A.R.; TRIVELIN, P.C.O.; BENDASSOLLI, J.A.; GASCHO, G.J. Calibration of a semi-open static collector for determination of ammonia volatilization from nitrogen fertilizers. Communications in Soil Science and Plant Analysis, v.30, p.389-406, 1999.

LUCCHESI, A.A. Utilização prática da análise de crescimento vegetal. Anais da Escola Superior de Agricultura Luiz de Queiroz, v.41, p.181-201, 1984.

MACHADO, E.C.; PEREIRA, A.R.; FAHL, J.L.; ARRUDA, H.V.; CIONE, J. Índices biométricos de duas variedades de cana-de-açúcar. Pesquisa Agropecuária Brasileira, v.17, p.1323-1329, 1982.

MALAVOLTA, E.; MORAES, M.F. Fundamentos do nitrogênio e do enxofre na nutrição mineral das plantas cultivadas. In: YAMADA, T.; ABDALLA, S.R.S. e; VITTI, G.C. (Ed.). Nitrogênio e enxofre na agricultura brasileira. Piracicaba: IPNI Brasil, 2007. p.189-249.
PING, J.; BREMER, E.; JANZEN, H.H. Foliar uptake of volatilized ammonia from surface-applied urea by spring wheat. Communications in Soil Science and Plant Analysis, v.31, p.165-172, 2000.

PRASERTSAK, P.; FRENEY, J.R.; DENMEAD, O.T.; SAFFIGNA, P.G.; PROVE, B.G.; REGHENZANI, J.R. Effects of fertilizer placement on nitrogen loss from sugarcane in tropical Queensland. Nutrient Cycling in Agroecosystems, v.62, p.229-239, 2002.

RAIJ, B.; CANTARELLA, H. Outras culturas industriais. In: RAIJ, B. van; CANTARELLA, H.; QUAGGIO, J.A.; FURLANI, A.M.C. (Ed.). Recomendações de adubação e calagem para o Estado de São Paulo. Campinas: Instituto Agronômico, 1997. p.233-243. (IAC. Boletim técnico, 100).

RAMESH, P.; MAHADEVASWAMY, M. Effect of formative phase drought on different classes of shoots, shoot mortality, cane attributes, yield and quality of four sugar cane cultivars. Journal of Agronomy and Crop Science, v.185, p.249-258, 2000.

ROCHETTE, P.; ANGERS, D.A.; CHANTIGNY, M.H.; MACDONALD, J.D.; BISSONNETTE, N.; BERTRAND, N. Ammonia volatilization following surface application of urea to tilled and no-till soils: a laboratory comparison. Soil and Tillage Research, v.103, p.310-315, 2009.

ROLIM, G.S.; SENTELHAS, P.C.; BARBIERI, V. Planilhas no ambiente EXCEL ${ }^{\mathrm{TM}}$ para os cálculos de balanços hídricos: normal, seqüencial, de cultura e de produtividade real e potencial. Revista Brasileira de Agrometeorologia, v.6, p.133-137, 1998.

SANTANA, M.J. de; CARVALHO, J. de A.; SOUZA, K.J. de; SOUSA, A.M.G. de; VASCONCELOS, C.L.; ANDRADE, L.A. de B. Efeitos da salinidade da água de irrigação na brotação e desenvolvimento inicial da cana-de-açúcar (Saccharum spp) e em solos com diferentes níveis texturais. Ciência e Agrotecnologia, v.31, p.1470-1476, 2007.

SANTOS, H.G. dos; JACOMINE, P.K.T.; ANJOS, L.H.C. dos; OLIVEIRA, V.A. de; OLIVEIRA, J.B. de; COELHO, M.R.; LUMBRERAS, J.F.; CUNHA, T.J.F. (Ed.). Sistema brasileiro de classificação de solos. 2.ed. Rio de janeiro: Embrapa Solos, 2006. 306p.

SIMÕES, M.S.; ROCHA, J.V.; LAMPARELLI, R.A.C. Growth indices and productivity in sugarcane. Scientia Agricola, v.62, p.23-30, 2005.

SOMMER, S.G.; SCHJOERRING, J.K.; DENMEAD, O.T. Ammonia emission from mineral fertilizers and fertilized crops. Advances in Agronomy, v.82, p.557-622, 2004.

TRIVELIN, P.C.O.; OLIVEIRA, M.W. de; VITTI, A.C.; GAVA, G.J. de C.; BENDASSOLLI, J.A. Perdas do nitrogênio da uréia no sistema solo-planta em dois ciclos de cana-de-açúcar. Pesquisa Agropecuária Brasileira, v.37, p.193-201, 2002.

VIEIRA, M.X.; TRIVELIN, P.C.O.; FRANCO, H.C.J.; OTTO, R.; FARONI, C.E. Ammonium chloride as nitrogen source in sugarcane harvested without burning. Revista Brasileira de Ciência do Solo, v.34, p.1165-1174, 2010.

VITTI, A.C.; TRIVELIN, P.C.O.; GAVA, G.J.C.; FRANCO, H.C.J.; BOLOGNA, I.R.; FARONI, C.E. Produtividade da cana-de-açúcar relacionada à localização de adubos nitrogenados aplicados sobre 
os resíduos culturais em canavial sem queima. Revista Brasileira de Ciência do Solo, v.31, p.491-498, 2007a.

VITTI, A.C.; TRIVELIN, P.C.O.; GAVA, G.J.C.; PENATTI, C.P.; BOLOGNA, I.R.; FARONI, C.E.; FRANCO, H.C.J. Produtividade da cana-de-açúcar relacionada ao nitrogênio residual da adubação e do sistema radicular. Pesquisa Agropecuária Brasileira, v.42, p.249-256, $2007 b$.
VITTI, G.C.; FARIA, M.R.M.; TOMASELLA, M.; GRANDO, N. Fontes de nitrogênio aplicadas em cobertura, nas culturas do trigo e da cevada em dois tipos de solo. Revista de Agricultura, v.83, p.197-207, 2008.

ZULLO JUNIOR, J.; ARRUDA, F.B. Programa computacional para ajuste de equações em dados experimentais. Campinas: Instituto Agronômico, 1987. 31p. (IAC. Boletim técnico, 113).

Recebido em 12 de abril de 2011 e aprovado em 19 de novembro de 2012 